\title{
On the variability of the quarter-diurnal tide in the MLT over Brazilian low-latitude stations
}

\author{
Amitava Guharay ${ }^{1 *}$, Paulo Prado Batista ${ }^{2}$, Ricardo Arlen Buriti ${ }^{3}$ and Nelson Jorge Schuch ${ }^{4}$
}

\begin{abstract}
The characteristic features of the quarterdiurnal tide (QDT) in the mesosphere and lower thermosphere (MLT) are investigated using meteor radar observations from three low-latitude southern hemispheric stations, Sao Joao do Cariri $\left(7.4^{\circ} \mathrm{S}, 36.5^{\circ} \mathrm{W}\right)$, Cachoeira Paulista $\left(22.7^{\circ} \mathrm{S}, 45^{\circ} \mathrm{W}\right.$ ) and Santa Maria $\left(29.7^{\circ} \mathrm{S}, 53.7^{\circ} \mathrm{W}\right)$ in 2005 . The QDT shows consistent appearance with a weak enhancement during late summer and fall interval. The QDT amplitudes are found to be much smaller $(<3 \mathrm{~m} / \mathrm{s})$ than the longer period tidal components most of the times of the year consistent with the previous investigations carried out from various locations over the globe. The vertical wavelength is found to reach up to $80 \mathrm{~km}$ in the MLT maximizing in winter although most of the times it remains within $20 \mathrm{~km}$. Therefore, based on the observed characteristics of the QDT, it is surmised that both the migrating and nonmigrating components are involved in manifestation of the QDT at present locations. Further detailed investigations are sought in connection with the important issues pertained to the actual excitation mechanisms and existing dominant QDT modes in the low-latitude MLT.
\end{abstract}

Keywords: Quarterdiurnal tide, Mesosphere and lower thermosphere, Meteor radar observations

\section{Introduction}

Gravity waves, tides and planetary waves with periods of a few minutes to days are most dominant dynamical entities responsible for modification of the ambient dynamics of the mesosphere and lower thermosphere (MLT). The atmospheric tides are one of the most prominent waves to transport significant energy from the lower atmosphere to the MLT where dynamical conditions are mostly controlled by the propagating and dissipating waves (Reddi et al. 1993; Walterscheid and Sivjee 2001; Guharay and Franke 2011; Guharay et al. 2013 and references therein). The tides are mainly generated due to absorption of the incoming solar insolation over various bands of electromagnetic spectrum by the atmospheric species, for example water vapor, ozone, atomic and molecular oxygen (Chapman and Lindzen 1970; Strobel 1978), etc.

\footnotetext{
*Correspondence: guharay@prl.res.in

${ }^{1}$ Space and Atmospheric Sciences Division, Physical Research Laboratory, Ahmedabad, GJ, India

Full list of author information is available at the end of the article
}

The latent heat release by the water vapor during condensation is another prominent source of tidal generation in the lower atmosphere (Forbes et al. 1999a). The tidal periods are sub-harmonic of the solar day, i.e., $24,12,8$, $6 \mathrm{~h}$ and so on, showing strongest amplitude for the diurnal $(24 \mathrm{~h})$ and semidiurnal ( $12 \mathrm{~h}$ ) components.

Among these major tidal components, the quarterdiurnal tide (6 h) (QDT) is least explored by observational and model studies due to its weak manifestation of significantly smaller amplitude as compared to other three dominant harmonics. However, it should be mentioned that the QDT could also be a major contributor to the MLT dynamics at times depending on ambient dynamical conditions as pointed out by observational and modeling investigations (Smith et al. 2004; Xu et al. 2014; Jacobi et al. 2017).

With the help of meteor wind measurements, Revah (1969) observed significant acoustic-gravity wave energy at periods 4, 6 and $8 \mathrm{~h}$ that were most probably manifestation of the tidal components. Since then, only a few studies investigated the characteristic features of the 
QDT in the neutral atmosphere and ionosphere. Tong et al. (1988) found a prominent signature of the QDT, which was comparable to the semidiurnal amplitude in the upper E-region ionosphere during winter over Arecibo. Later, Morton et al. (1993) found significant role of the 6-h period wind on the variability of the tidal ion layer (TIL) in the D and E region of the ionosphere during early January over Arecibo using long-term observations. They concluded that the presence of the 6-h wind was due to a nonlinear frequency doubling of the semidiurnal tide rather than an independent tidal component since the former was phase-locked to the latter.

Sivjee and Walterscheid (1994) reported a zonally symmetric QDT oscillation in the airglow intensity and temperature in winter southern polar mesopause region. They indicated possible driving sources as heating by the stratospheric ozone or nonlinear interaction between the migrating tides in the lower atmosphere. They also pointed out the possibility of interaction between the migrating tides and topography for the observed zonally symmetric QDT. She et al. (2002) investigated various tidal components in the MLT using lidar temperature observations from Fort Collins $\left(41^{\circ} \mathrm{N}, 105^{\circ} \mathrm{W}\right)$ and found irregular phase variation of the QDT with altitude unlike the diurnal and semidiurnal tides exhibiting clear downward phase propagation.

Utilizing meteor wind observations from a high-latitude station, Esrange $\left(60^{\circ} \mathrm{N}, 21^{\circ} \mathrm{E}\right)$, and numerical model simulation, Smith et al. (2004) found the strongest QDT activity in midwinter with smaller amplitude at low latitudes. They also inferred that the migrating tides were dominant at low latitude and nonmigrating tides took over at higher latitude. Using satellite-based microwave limb sounder (MLS) measurements Xu et al. (2012) studied the role of the ozone heating in the stratosphere and lower mesosphere in exciting various tidal components and reported higher QDT amplitude during solstices, especially in winter than equinox intervals.

With the help of Sounding of the Atmosphere using Broadband Emission Radiometry (SABER) measurements onboard the Thermosphere-Ionosphere-Mesosphere Energetics and Dynamics (TIMED) satellite, $\mathrm{Xu}$ et al. (2014) concluded that the nonlinear interactions between the migrating diurnal tide and stationary planetary wave (SPW) could produce the nonmigrating diurnal and terdiurnal tides and these secondary tides might interact further to generate the QDT in the middle atmosphere. They also mentioned that such interactions could take place more favorably beyond tropical latitudes due to weak SPWs at tropical regions. Of late, Azeem et al. (2016) investigated the characteristics of the migrating QDT using temperature measurements from the Near-Infrared Spectrometer (NIR) on Remote Atmospheric and Ionospheric Detection
System experiment on the International Space Station and SABER. They found significant QDT activity at low- and midlatitudes in terms of the derived Hough mode structures. Of late, utilizing long-term meteor wind data from two mid-latitude stations, Collm $\left(51^{\circ} \mathrm{N}, 13^{\circ} \mathrm{E}\right)$ and Obninsk $\left(55^{\circ} \mathrm{N}, 37^{\circ} \mathrm{E}\right)$, Jacobi et al. (2017) studied seasonal and interannual variability of the QDT. They observed winter enhancement with increasing trend of the tidal amplitude over long term and indicated a possibility of major contribution from the migrating QTD at the observational sites.

From the available literatures as depicted above, it is evident that only a handful of investigations related to the QDT have been carried out so far, and hence as a matter of fact, our understanding is also very limited. Another very important point to note is that there is hardly any exclusive systematic study of the QDT from low-latitude region so far. Therefore, considering existing limitation in our understanding due to lack of sufficient studies, an attempt has been made in the present work to characterize the least explored tidal signature from three low-latitude stations, Sao Joao do Cariri (CA) $\left(7.4^{\circ} \mathrm{S}, 36.5^{\circ} \mathrm{W}\right)$, Cachoeira Paulista (CP) $\left(22.7^{\circ} \mathrm{S}, 45^{\circ} \mathrm{W}\right)$ and Santa Maria $(\mathrm{SM})\left(29.7^{\circ} \mathrm{S}, 53.7^{\circ} \mathrm{W}\right)$. Our study aims to describe the latitudinal and seasonal variability of the QDT in the MLT utilizing meteor wind observations.

\section{Instrument and data analysis}

The meteor radar systems operating at CA, CP and SM are basically all-sky interferometric radars operating at $35.24 \mathrm{MHz}$ frequency with peak power $12 \mathrm{~kW}$, pulse repetition frequency $2 \mathrm{kHz}$ and pulse width $13 \mu \mathrm{s}$. A threeelement Yagi antenna is used for transmitting the radio signal. For receiving backscattered meteor echoes, five twoelement Yagi antennas aligned along two orthogonal baselines with one antenna common to the both are utilized. The received signal is analyzed to derive range, position of the echoes and horizontal velocity of the wind. The detailed algorithm for finding the aforementioned parameters can be found in a paper by Hocking et al. (2001). The radars provide useful echo-associated information in the altitude range $80-100 \mathrm{~km}$. For the present study, the radar-obtained zonal and meridional winds with horizontal and vertical resolutions of $1 \mathrm{~h}$ and $3 \mathrm{~km}$, respectively, for the year 2005 are utilized. The observation year is chosen as per minimum extant data gaps over all three stations under consideration. Only those data points of horizontal winds are utilized for the present analysis where uncertainties are less than $1 \mathrm{~m} / \mathrm{s}$ considering small amplitude of the QDT.

The hourly winds are undergone harmonic analysis by using least square fit method to estimate dominant tidal amplitude and phase over a window of $192 \mathrm{~h}$ (width) using the formula as follows. 


$$
Y(t)=Y_{\mathrm{o}}+\sum_{n=1,2,3,4} A_{n} \operatorname{Sin}\left[\frac{2 \pi n}{24}\left(t-\varphi_{n}\right)\right]
$$

where $n=1,2,3$, 4 signifies diurnal, semidiurnal, terdiurnal and quarterdiurnal components. $Y(t)$ is zonal or meridional wind, and $Y_{\mathrm{o}}$ is the mean over the fitting window, i.e., 192 h. $t$ denotes the corresponding local time in hours of the winds. $\phi$ denotes the phases in hours of the respective tidal components. The linear trend is removed from the data over the specified window before performing harmonic analysis. The window is slid progressively by 1 day to obtain daily amplitudes and phases of the concerned waves. The amplitudes and phases are calculated for those cases where a number of hourly data points within a window are greater than one-eighth of the window width, i.e., $>24$ points. Since the longitudinal differences between the stations are appreciable as compared to the period of the QDT, the phases at SM, CP and CA are added by $0,0.58$ and $1.15 \mathrm{~h}$, respectively, to consider the actual local time differences between the stations. The monthly mean amplitudes and phases at a particular altitude bin are estimated by vector averaging of the daily values. The vertical wavelengths are calculated from the slope (linear fit) of the vertical phase profiles $(81-99 \mathrm{~km})$ for those days where a clear vertical phase propagation direction is identifiable.

\section{Results}

Figure 1 plots the typical residual zonal/meridional winds at $90 \mathrm{~km}$ after removing the diurnal and semidiurnal tides from the actual data over the three locations where 6-h oscillation is found to be very prominent. Only those days showing evident 6 -h period as can be identified visibly are selected for this purpose. A least square sinusoidal fit to the residual winds reveals amplitudes of $7.9 \pm 2.1,7.3 \pm 1.6,14.0 \pm 1.3 \mathrm{~m} / \mathrm{s}$ and periods of $6.0 \pm 0.2$, $6.0 \pm 0.2,6.2 \pm 0.1 \mathrm{~h}$ at CA (meridional wind), CP (zonal wind) and SM (meridional wind), respectively. Since the 6-h periodicity shows significant amplitude over all three locations, further analyses of this component are carried out in the rest of the manuscript.

Now the question arises whether the observed 6-h oscillation is a component of Lamb waves. However, the Lamb waves are found in the polar region only (Hernandez et al. 1992; Forbes et al. 1999b), which rules out the possibility of the Lamb waves. Now the next question that comes in the mind is whether the manifested wave is a gravity wave since the QDT is generally very weak in the low-latitude region. If it is a gravity wave, its appearance would be irregular or in other words, there should not be any phase locking over a long period of time unlike tides. To verify the
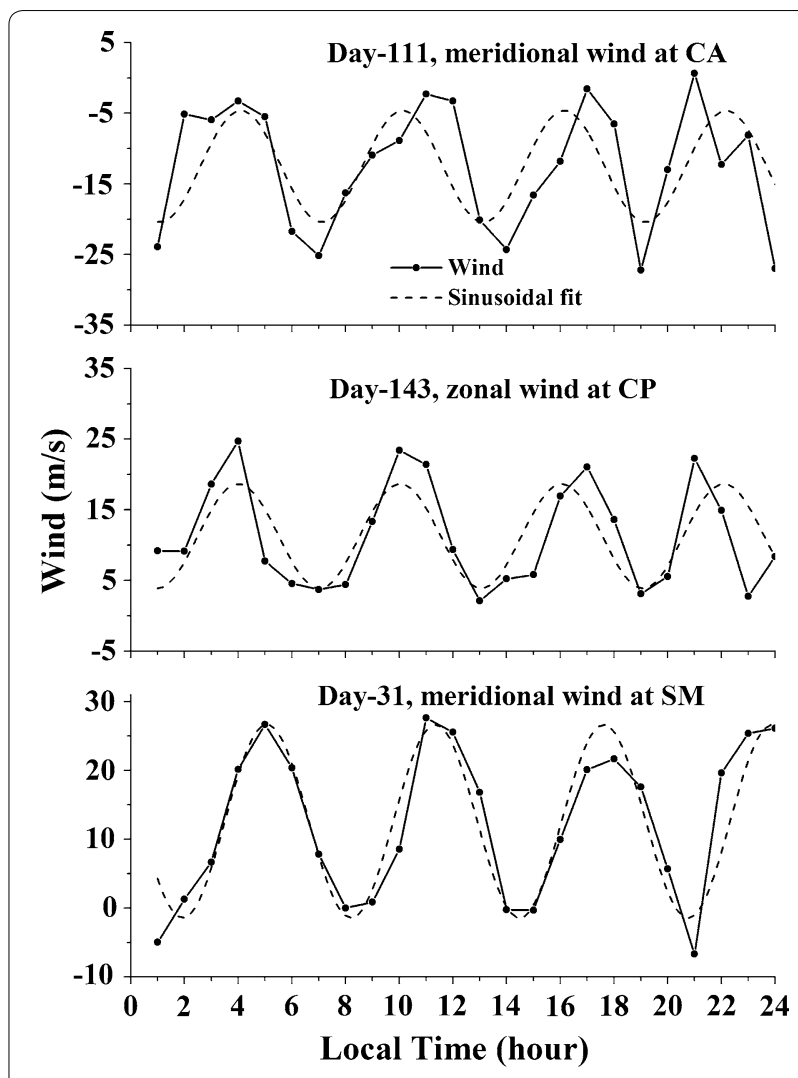

Fig. 1 Typical residual winds at $90 \mathrm{~km}$ on removing the diurnal and semidiurnal components show prominent $6-h$ wave at a CA in the meridional wind on $111 \mathrm{DY}, \mathbf{b}$ CP in the zonal wind on $143 \mathrm{DY}$ and $\mathbf{c}$ $\mathrm{SM}$ in the meridional wind on $31 \mathrm{DY}$

feature, the daily wind data are undergone high-pass filter with cutoff at $7 \mathrm{~h}$ to avoid higher period tides and waves. Then, the daily filtered data are undergone composite averaging over the year 2005 to obtain a singleday $(24 \mathrm{~h})$ mean profile. The composite mean profiles are plotted in Fig. 2 for all the locations in both the zonal and meridional winds separately. It is interesting to note that all the plots show clear four-crest and fourtrough structure over $24 \mathrm{~h}$ span indicating 6-h oscillation to be very regular and most dominant wave feature among the waves with periods less than $7 \mathrm{~h}$ in the MLT and hence it confirms the existence of the QDT at the present sites.

The daily QDT amplitude at a particular altitude bin is estimated using Eq. (1). Figure 3 shows the daily vertical (81-99 km) mean QDT amplitude in the year 2005 with respect to day of year (DY). The horizontal straight line denotes mean amplitude during the observational span. A 31-point running average profile is also shown by bold line to decipher broad behavior of the tidal variability. All the subplots show multiple spikes in the amplitude over time. The meridional 

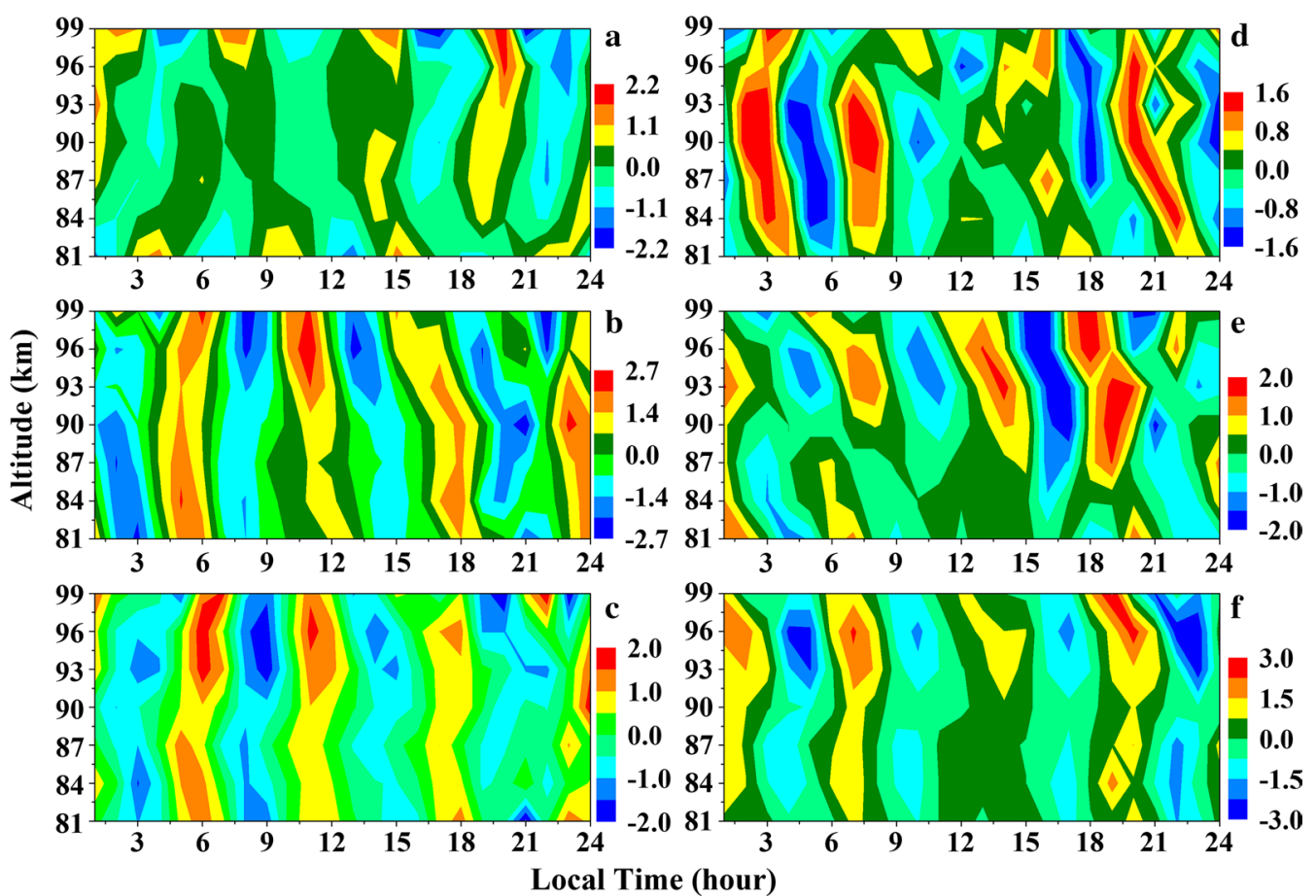

Fig. 2 Daily composite mean wind profiles in 2005 undergone high-pass filter with cutoff at $7 \mathrm{~h}$ are shown for $\mathbf{a}$ zonal wind at CA, $\mathbf{b}$ zonal wind at $\mathrm{CP}, \mathbf{c}$ zonal wind at $\mathrm{SM}, \mathbf{d}$ meridional wind at $\mathrm{CA}$, e meridional wind at $\mathrm{CP}$ and $\mathbf{f}$ meridional wind at $\mathrm{SM}$

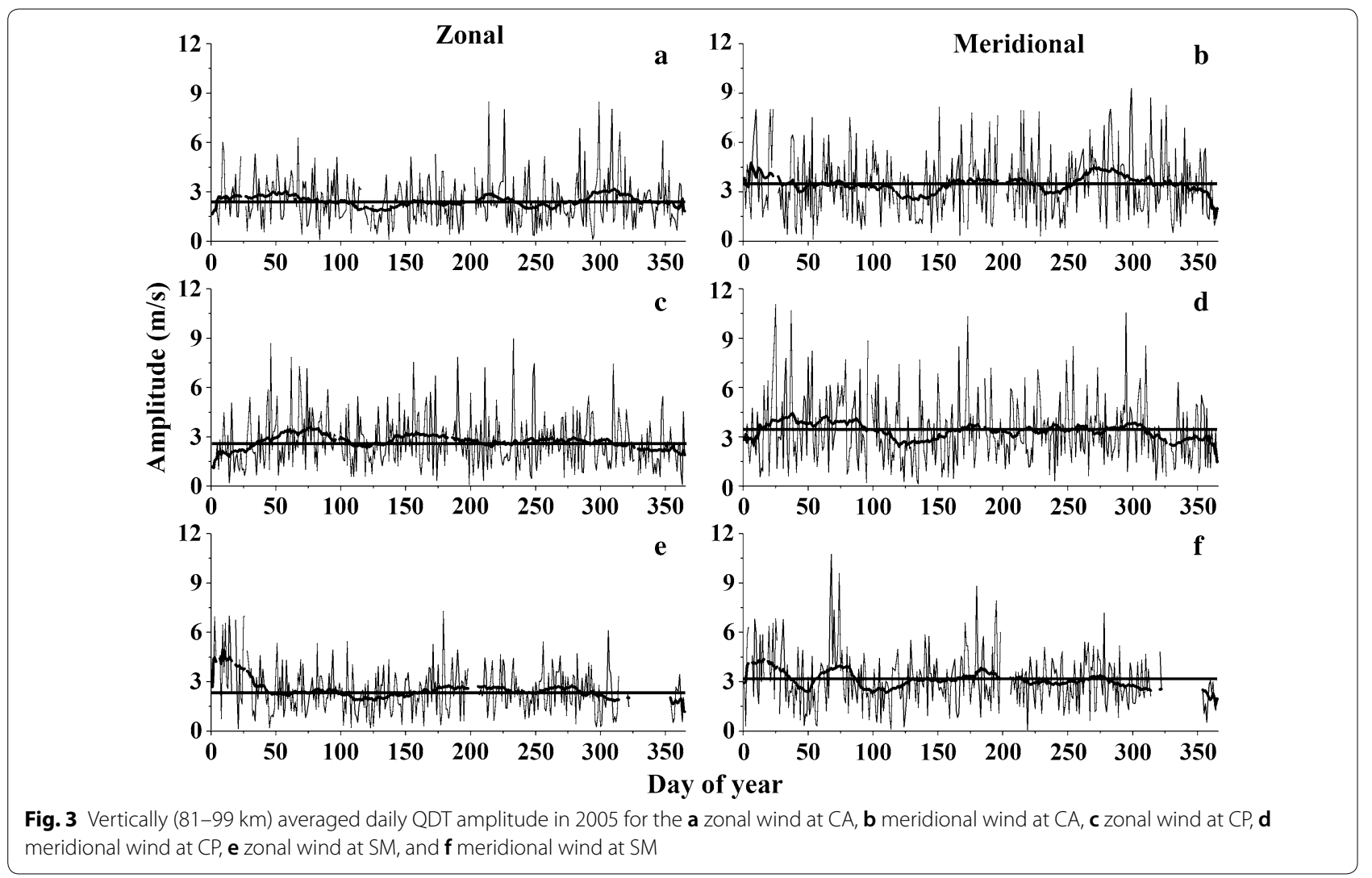


mean amplitudes are always higher than the zonal ones at all the locations. At CA, relatively higher amplitude is found in late summer (20-30 DY) in the meridional wind although the zonal component variability is not very prominent. On the other hand, large amplitudes in both the winds are found in fall (70-80 DY) at CP. At $\mathrm{SM}$, almost coincident peaks in the amplitude in both the winds are visible in late summer (1-10 DY) and fall (70-80 DY).

In order to delineate the seasonal variability with more details, the vertical profiles of the monthly mean amplitude are shown by contour plots in Fig. 4. In general, the amplitude increases with altitude and is greater in the meridional wind as compared to the zonal wind. At CA, the amplitude is weakest in the lower MLT during winter (May-July) as evident in both the wind components. The amplitude profiles at all the sites show a common minimum around early summer (NovemberDecember). Almost all the subplots show high amplitude during late summer and fall similar to the result of Fig. 3, although a few embedded small patches of minima could also be identified.

Figure 5 shows the occurrence frequency of the estimated amplitudes with a bin size of $1 \mathrm{~m} / \mathrm{s}$ for the whole year in the MLT. The QDT amplitude corresponding to the maximum occurrence frequency is found to be less than $3 \mathrm{~m} / \mathrm{s}$ in all the cases, indicating its weaker activity as compared to the longer period tides most of the time of the year. The maximum frequency of occurrence over all the sites corresponds to an amplitude range of $2-3 \mathrm{~m} / \mathrm{s}$ in the meridional wind. Except $\mathrm{CP}$, the amplitude range corresponding to the maximum occurrence frequency is found to be a bit smaller, i.e., $1-2 \mathrm{~m} / \mathrm{s}$ in the zonal wind.

The monthly mean vertical profiles of the amplitude at the observational stations are shown in Fig. 6 for the zonal wind. The horizontal bars represent the uncertainties of the same. In general, the amplitude is maximum at the top $(99 \mathrm{~km})$. The amplitude shows an increasing trend above $93 \mathrm{~km}$ except at CP in March. A remarkable similarity in the vertical profiles among all the stations is found during August-September and NovemberDecember intervals. In August and September, there is a common trend of almost constant amplitude up to $93 \mathrm{~km}$ and hereafter it increases monotonically.

Figure 7 shows the monthly mean vertical profiles of the amplitude in the meridional wind. A significant agreement among the stations is observed in a few months except January-April, October and December. The profiles containing good agreement among the stations over various months show almost monotonically

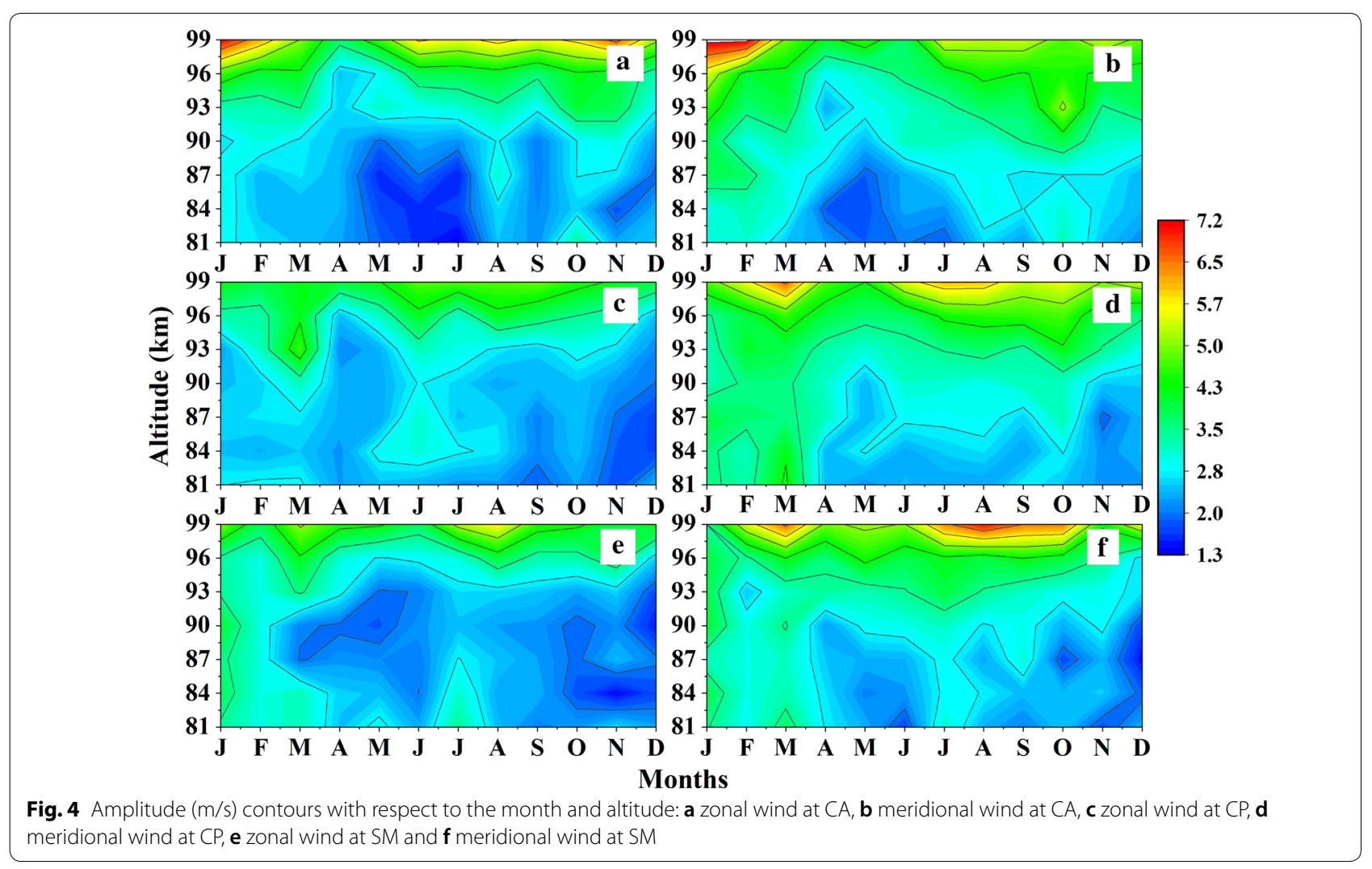




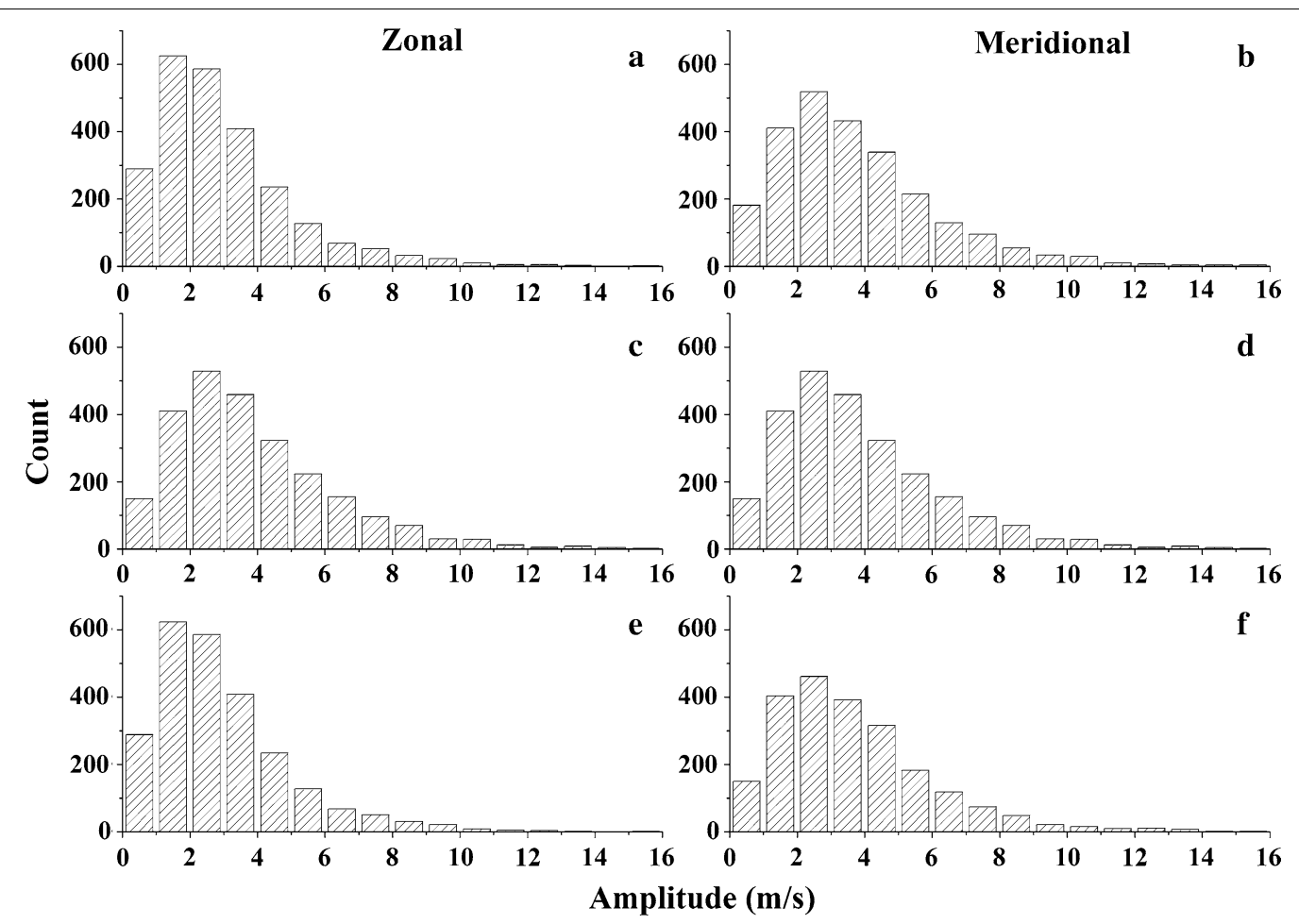

Fig. 5 Occurrence frequency of the QDT amplitude over the year for a zonal wind at $C A, \mathbf{b}$ meridional wind at $C A, \mathbf{c}$ zonal wind at $C P$, $\mathbf{d}$ meridional wind at $C P$, e zonal wind at $S M$, and $\mathbf{f}$ meridional wind at $S M$

increasing amplitudes in the MLT. The overall amplitudes in the meridional wind are higher than the zonal ones.

The monthly mean vertical profiles of the phase (hours) in the zonal wind are shown in Fig. 8. The best agreement among the stations is found in March. It is interesting to note a remarkable agreement between a pair of phase profiles, for example CA and SM in March, CP and SM in May, July, August-December interval. Although the phase profiles at $\mathrm{CP}$ and $\mathrm{SM}$ resemble well most of the times, the phases at CA differ significantly with other two sites. The most of the profiles show clear upward phase propagation direction although some of them are too irregular. It should be noted that the initial phase values for all the altitude bins are shown in the plot (unlike the maximum phase values which would be downward directed) implying upward wave propagation (Guharay et al. 2017).

Figure 9 plots the monthly mean vertical phase profiles in the meridional wind. The profiles are more irregular in the meridional wind than the zonal ones although vertical phase propagation direction is discernible. Good agreement between the phase profiles at CP and SM is found in March, which is found to be very frequent in the zonal wind as mentioned before. Furthermore, the phase profiles at CA exhibit considerable difference with the ones at $\mathrm{CP}$ and SM.The detailed implication of the phase profile behavior will be discussed in the next section.

The vertical wavelength (VW) calculated from the slope of the daily vertical phase profiles as discussed in "Instrument and data analysis" section at the stations for both the wind components is shown in Fig. 10. The bold line in each subplot denotes a 31-point running average. The vertical bars denote the uncertainties in the estimated values. The VW shows a large range of variability (up to $80 \mathrm{~km}$ ). Although the VW shows high fluctuations, an overall enhancement is found during winter $(\sim 150$ $240 \mathrm{DY})$. On average, the VW attains a value close to $20 \mathrm{~km}$.

Figure 11 shows frequency of occurrence of the VW with bin size $10 \mathrm{~km}$. It is interesting to note that the most common feature among all the stations and winds is maximum frequency of occurrence corresponding to VW bin of $10-20 \mathrm{~km}$ followed by $20-30 \mathrm{~km}$.

\section{Discussion}

In the present study, we investigate the comparative characteristic features of the QDT in the MLT from three low-latitude Southern hemispheric stations using meteor radar observations in 2005. Although variability of the diurnal, semidiurnal and terdiurnal tides from the same locations was reported by a few previous studies 


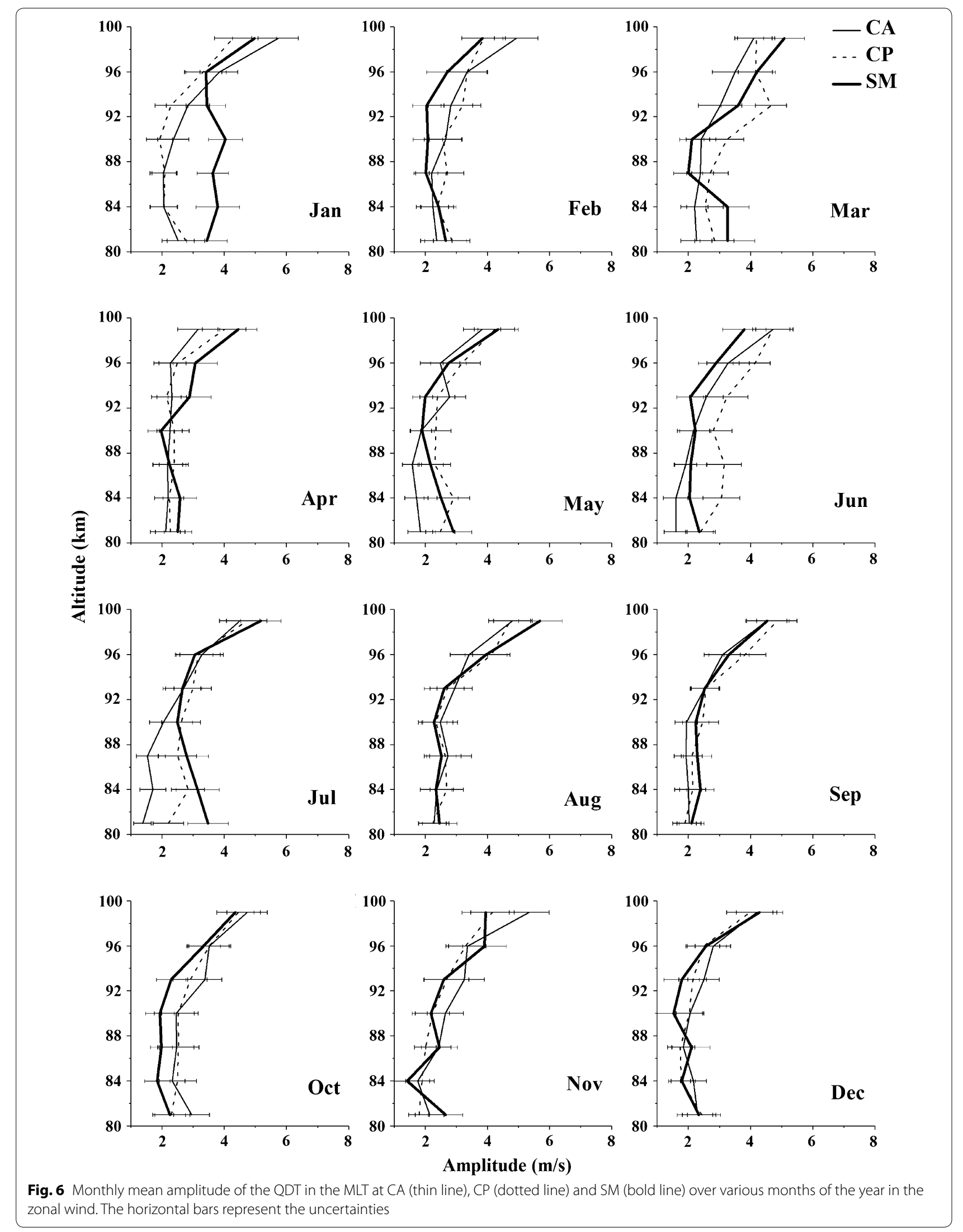




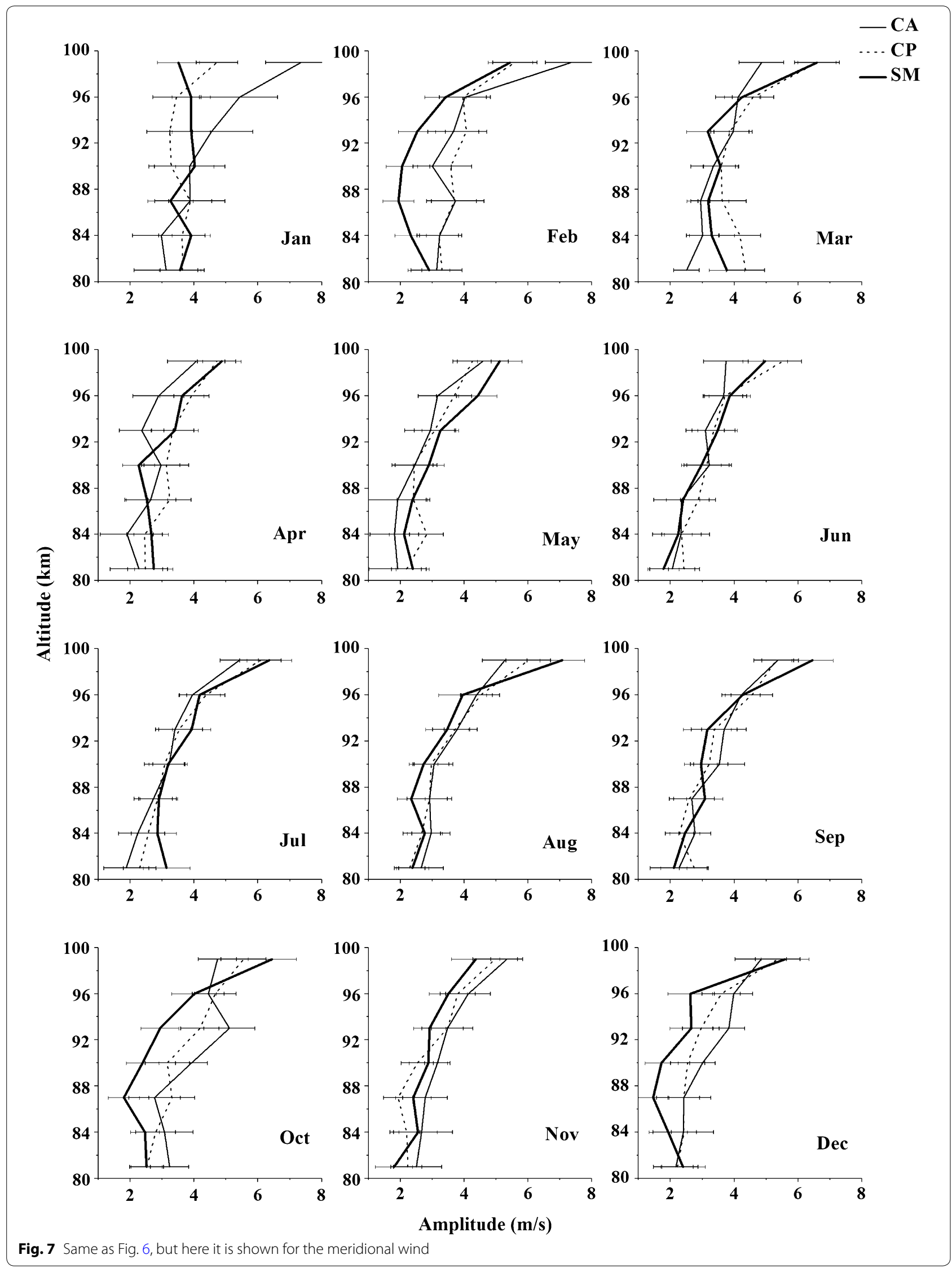




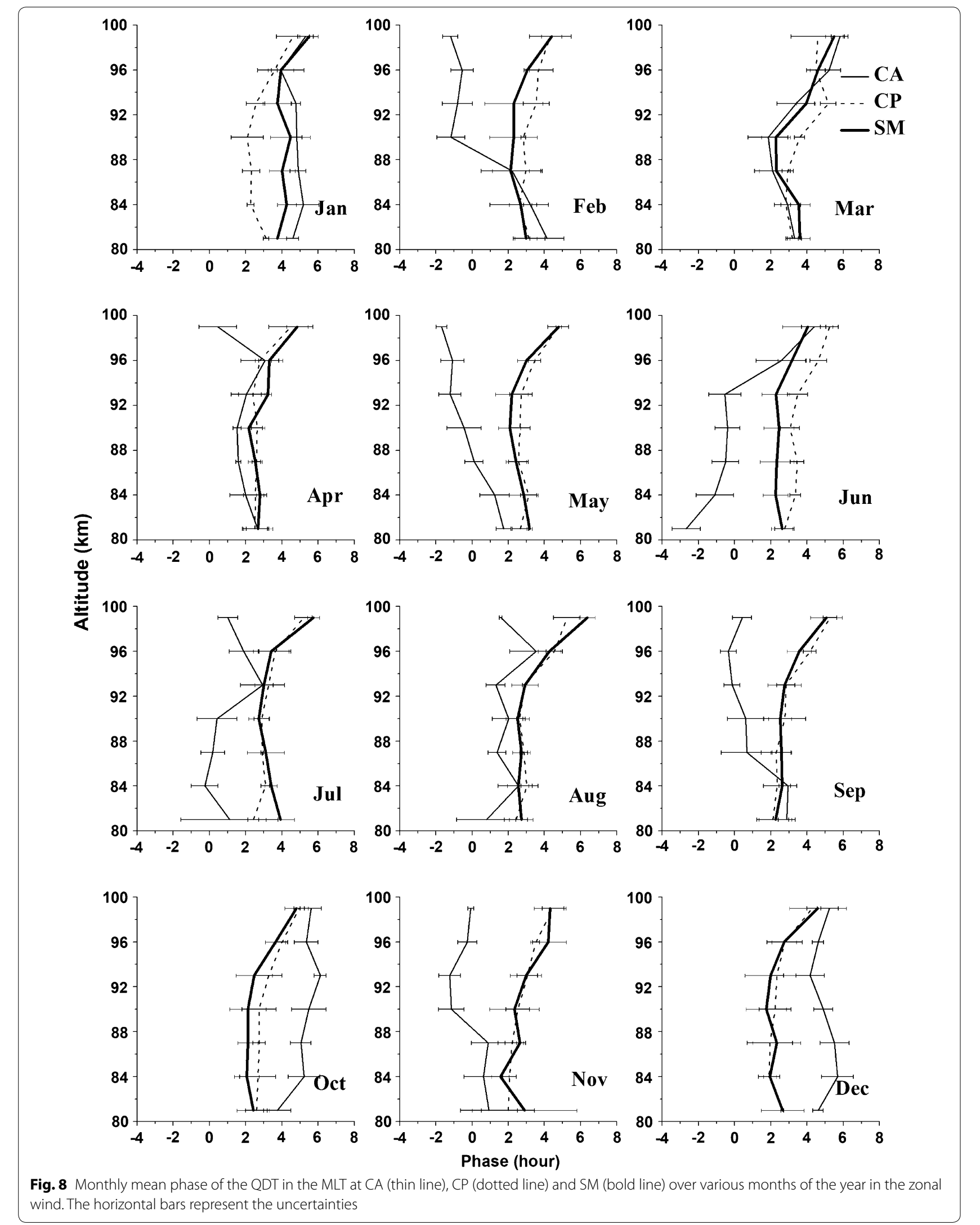




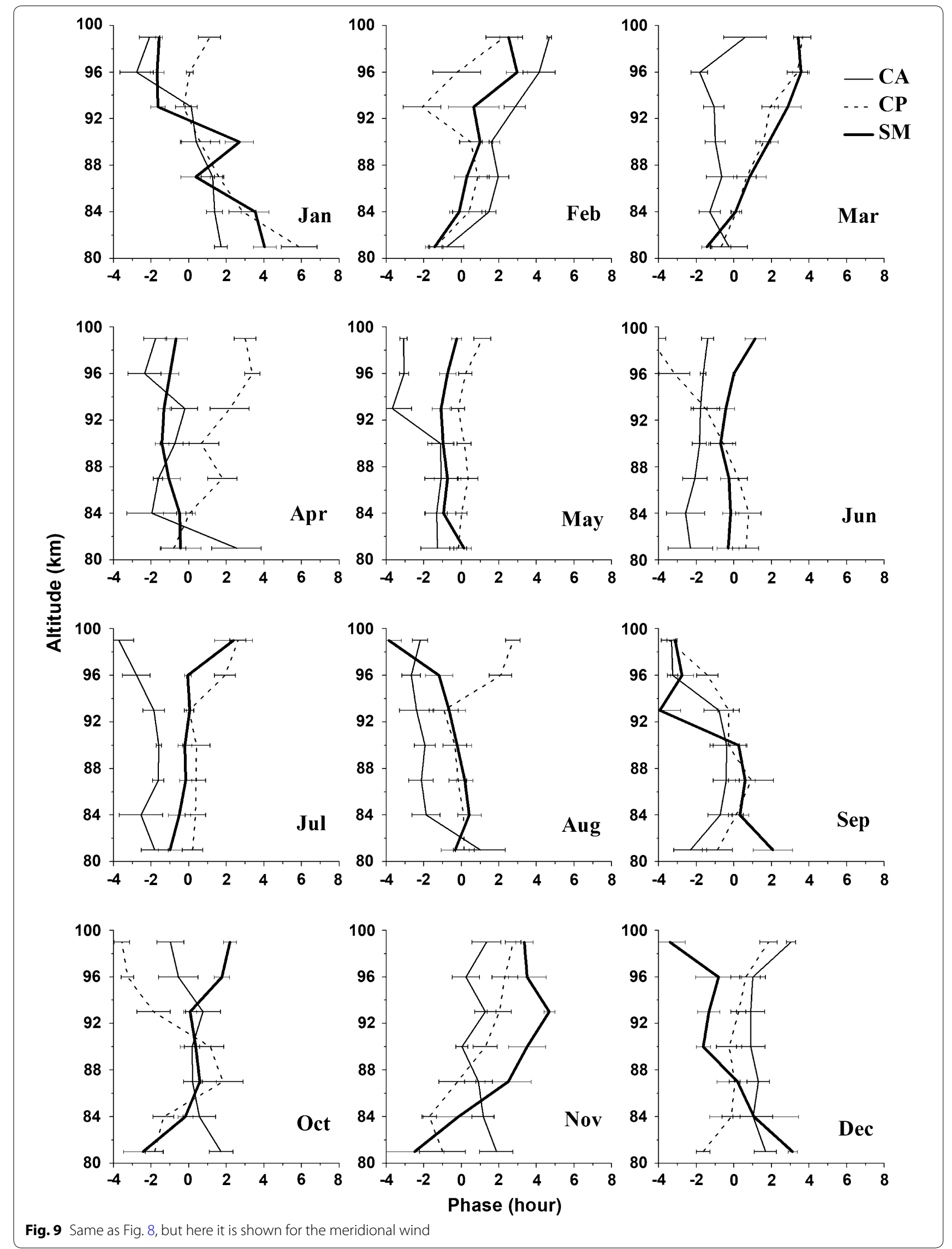



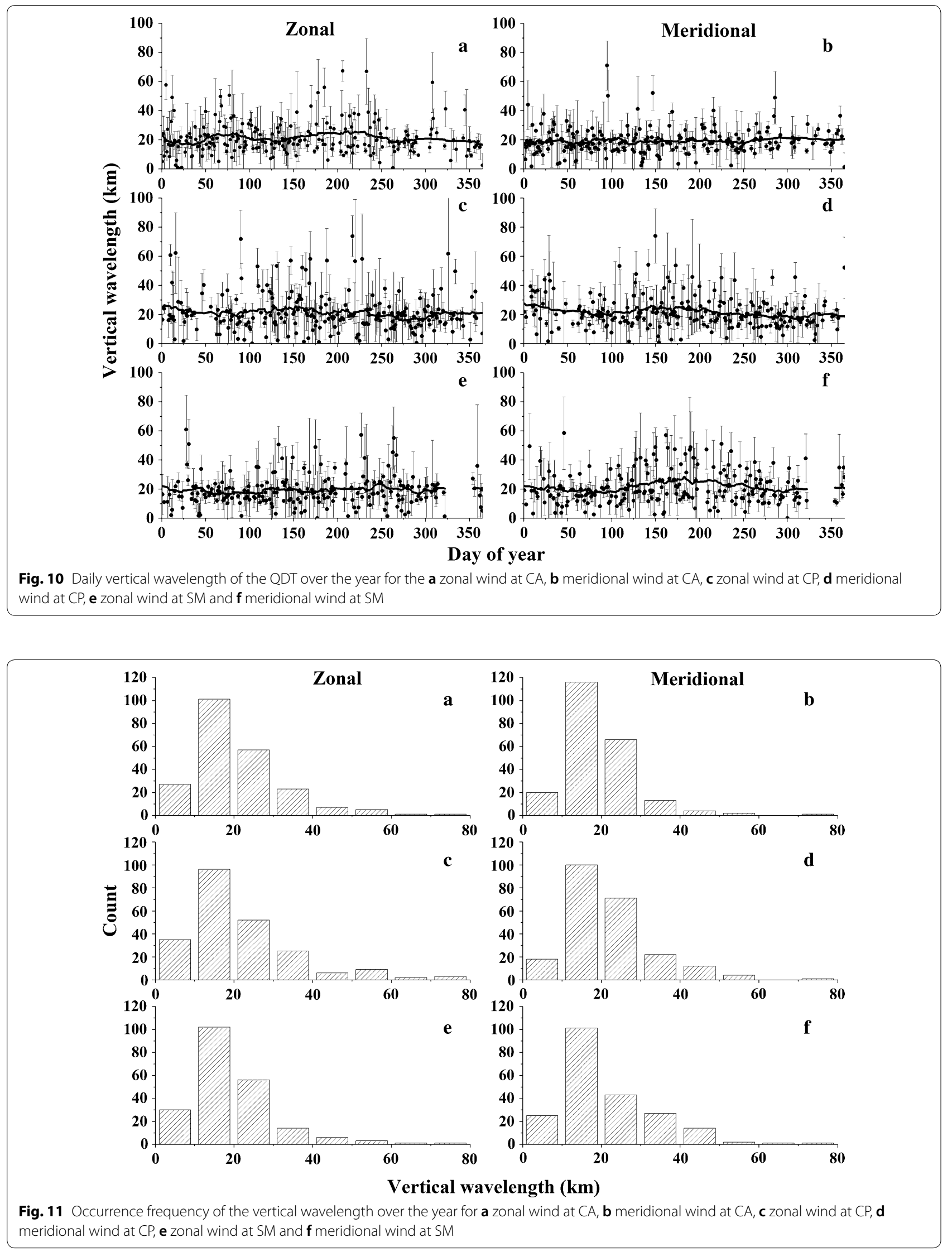
(Batista et al. 2004; Buriti et al. 2008; Andrioli et al. 2009; Guharay et al. 2013, 2015), investigation of the QDT remained untouched so far. The QDT signature in the present study is found to be quite regular over the year with a weak seasonal variability although the amplitude is much smaller than the same of the diurnal, semidiurnal and terdiurnal components as shown by the past investigators from the same observational sites. As mentioned before, most of the studies in the past related to the QDT were carried out from the high- and midlatitude stations, and the behavior of the tidal variability in the present study is found to be different to some extent due to varying dynamical conditions with latitude.

The observed amplitude of the QDT from the present study rarely crosses $10 \mathrm{~m} / \mathrm{s}$ in most cases, and the maximum frequency of occurrence is found to be well within $3 \mathrm{~m} / \mathrm{s}$, which is consistent with previous midlatitude observations (Jacobi et al. 2017). Using layer trajectory modeling study from northern hemispheric low-latitude station, Tong et al. (1988) showed monotonic increase of the QDT amplitude in the MLT with a value less than $2 \mathrm{~m} / \mathrm{s}$ near $100 \mathrm{~km}$. This result agrees well with the present southern hemispheric low-latitude study as we notice increase of amplitude above $93 \mathrm{~km}$ in certain months as mentioned in the last section. They concluded that generation of the QDT was a result of nonlinearity in the E-region tidal system, possibly a consequence of frequency doubling of the semidiurnal tide since the effect of direct solar forcing was not very evident. However, they expected its existence during winter months unlike the present study as we found weak enhancement during late summer and fall intervals.

The vertical amplitude profiles (Figs. 6, 7) over the three stations showed good resemblance in certain months. A handful of the previous studies from the high and polar latitudes concluded that the QDT was a zonally symmetric or stationary oscillation excited due to incident solar radiation (Walterscheid and Sivjee 1996, 2001). Although excitation of both the migrating tide and stationary tide is very similar, i.e., solar forcing, since the present study is based on the observations from the low latitude, possibility of the migrating tide is more likely than the latter. Before we discuss further, we would like to clarify that by the term nonmigrating tide, we mean all the available nonmigrating components of the concerned tide except the stationary component $(s=0)$ in the following discussion as the stationary tide is being treated as an independent entity. Generation of the nonmigrating QDT due to nonlinear interaction between the semidiurnal tides or frequency doubling could also be another possible mechanism as pointed out by Morton et al. (1993). Another possibility of the nonmigrating QDT generation could be due to nonlinear interaction between diurnal tide and terdiurnal tide (Xu et al. 2014). Kovalam and Vincent (2003) interpreted that the 6-h wave with zonal wave number 1 in the winds over southern hemispheric midlatitude and polar stations was a nonmigrating QDT driven by nonlinear interaction. However, in the present study, we have not looked details into the generation mechanism of the QDT as the present theme is to characterize the weak signature of the QDT from the low latitudes. Detailed study of the excitation mechanism of the QDT could be an interesting topic for future study.

With the observations and modeling study from the high latitude, Smith et al. (2004) concluded that the wintertime enhancement of the QDT was due to direct solar forcing although indirect excitation of the same was also supposed to be effective. Their global model result indicated dominance of the migrating tide throughout the globe except at poles. They reported monthly mean amplitude of the QDT could go up to $5 \mathrm{~m} / \mathrm{s}$ in the upper MLT which is smaller than our observed maximum value of $\sim 8 \mathrm{~m} / \mathrm{s}$ in the meridional wind.

It is interesting and important to note a remarkable difference in the seasonal enhancement of the tidal amplitude in the MLT between the previous and the present studies. As discussed before, all the previous investigations from mid- and high latitudes reported prominent wintertime peak. However, we find larger tidal amplitude in late summer and fall intervals as compared to the rest of the year. Such enhancement in the tidal amplitude in late summer and fall at present latitudes may be conceived to be contributed by the enhanced winter (Northern) hemispheric QDT as reported by the past investigators (Sivjee and Walterscheid 1994; Morton et al. 1993; Walterscheid and Sivjee 1996; Jacobi et al. 2017). However, with limited investigation from the present sites, it is difficult to establish a link between the two hemispheres and associated inter-hemispheric dynamical coupling and hence further extensive study in the future is indispensable to obtain better insight into the actual processes responsible for its generation in the southern hemisphere low latitudes.

The phase profiles (Figs. 8, 9) exhibit good agreement between CA, CP and SM in certain months most probably owing to the similar excitation mechanisms/ modes of oscillations since all the stations are located at low latitudes. The prevailing irregular vertical behavior of the phase as observed in the present results was also noted by the past investigators (She et al. 2002). Although considerable agreement is found very often in the phase profiles over three sites, large differences among them especially between CA and other two sites as pointed out in the previous section are also evident. The observed differences could be conceived to be due to the latitudinal variability of the QDT. The phase profiles 
in the meridional wind showing larger irregular behavior than the zonal one may be attributed to the influence of the multiple QDT modes containing greater meridional amplitudes as compared to the zonal ones due to polarization.

The VW shows winter maximum in consistent with a few past investigations (Smith et al. 2004; Jacobi et al. 2017). Azeem et al. (2016) found the VWs of the migrating component generally larger than $100 \mathrm{~km}$ which are higher than the present results. Smith et al. (2004) found seasonal mean VW in the range $\sim 28-55 \mathrm{~km}$ that is well within our observed range. However, Jacobi et al. (2017) observed generally higher values $(>100 \mathrm{~km})$ of the VW than the present finding in winter. Nevertheless, their estimated VW $(\sim 20 \mathrm{~km})$ in summer agrees well with the present study. We observed maximum occurrence frequency of the VW in the range of $10-20 \mathrm{~km}$. Small VW may indicate a possible contribution of the nonmigrating tides toward the observed QDT activity although it could not be guaranteed as other physical processes may also result in small vertical wavelength.

\section{Summary and conclusions}

The features of the QDT are investigated from three lowlatitude Southern hemispheric stations using meteor wind observations. The estimated amplitude is found to be within $3 \mathrm{~m} / \mathrm{s}$ most of the times that is significantly less than the other tidal components as shown by the previous investigators from the same locations. The tidal amplitude increases monotonically in the upper MLT. The seasonal variability is not found to be very prominent although a weak peak during late summer and fall interval is visible. The migrating modes are believed to play a major role to the total tidal activity at present locations although nonmigrating components may also be involved to some extent and it could only be ascertained with the help of global observations and/or modeling studies. The monthly mean tidal behavior reveals remarkable similarity between the stations during certain months of the year. The QDT activity at present locations in summer may be caused by frequency doubling of the semidiurnal tide. The nonlinear interactions may also be dominant to excite the short-period tide in other seasons. However, for clear understanding of the actual mechanisms responsible for the weak QDT activity in the southern hemisphere low latitudes, further extensive study is necessary which could be pursued in the future.

\section{Authors' contributions}

AG conceived the ideas and carried out analyses of the study. PPB carried out radar data processing and also assisted in manuscript preparation. RAB and NJS participated in the operation and data collection of the meteor radar. All authors read and approved the final manuscript.

\begin{abstract}
Author details
${ }^{1}$ Space and Atmospheric Sciences Division, Physical Research Laboratory, Ahmedabad, GJ, India. ${ }^{2}$ Aeronomy Division, National Institute for Space Research (INPE), São José dos Campos, SP, Brazil. ${ }^{3}$ Federal University of Campina Grande, Campina Grande, PB, Brazil. ${ }^{4}$ Southern Regional Space Research Center-CRS/COCRE/INPE-MCTIC, Santa Maria, RS, Brazil.
\end{abstract}

\section{Acknowledgements}

The authors gratefully acknowledge the comments and suggestions provided by the reviewers and editor to improve the manuscript content.

\section{Competing interests}

The authors declare that they have no competing interests.

Availability of data and materials

Please contact author for data requests.

Funding

The present work is supported by the Department of Space (Government of India), National Institute for Space Research, Southern Regional Center for Space Research, Federal University of Campina Grande, National Council for Scientific and Technological Development (Government of Brazil), Sao Paulo Research Foundation (Sao Paulo, Brazil).

\section{Publisher's Note}

Springer Nature remains neutral with regard to jurisdictional claims in published maps and institutional affiliations.

Received: 5 April 2018 Accepted: 14 August 2018

Published online: 23 August 2018

\section{References}

Andrioli VF, Clemesha BR, Batista PP, Schuch NJ (2009) Atmospheric tides and mean winds in the meteor region over Santa Maria $\left(29.7^{\circ} \mathrm{S}, 53.8^{\circ} \mathrm{W}\right) . \mathrm{J}$ Atmos Sol Terr Phys 71:1864-1876

Azeem I, Walterscheid RL, Crowley G, Bishop RL, Christensen AB (2016) Observations of the migrating semidiurnal and quaddiurnal tides from the RAIDS/NIRS instrument. J Geophys Res Space Phys 121:4626-4637. https ://doi.org/10.1002/2015JA022240

Batista PP, Clemesha BR, Tokumoto AS, Lima LM (2004) Structure of the mean winds and tides in the meteor region over Cachoeira Paulista, Brazil $\left(22.7^{\circ} \mathrm{S}, 45^{\circ} \mathrm{W}\right)$ and its comparison with models. J Atmos Sol Terr Phys 66:623-636

Buriti RA, Hocking WK, Batista PP, Medeiros AF, Clemesha BR (2008) Observations of equatorial mesospheric winds over Cariri $\left(7.4^{\circ} \mathrm{S}\right)$ by a meteor radar and comparison with existing models. Ann Geophys 26:485-497

Chapman S, Lindzen RS (1970) Atmospheric tides. D. Reidel, Hingham

Forbes JM, Hagan ME, Zhang X, Hackney J (1999a) Upper atmosphere tidal variability due to latent heat release in the tropical troposphere. Adv Space Res 24(11):1515-1521. https://doi.org/10.1016/S0273 $-1177(99) 00873-X$

Forbes J, Palo S, Zhang X, Portnyagin Y, Makarov N, Merzlyakov E (1999b) Lamb waves in the lower thermosphere: observational evidence and global consequences. J Geophys Res 104:17107-17115

Guharay A, Franke SJ (2011) Characteristics of the semidiurnal tide in the MLT over Maui $\left(20.75^{\circ} \mathrm{N}, 156.43^{\circ} \mathrm{W}\right)$ with meteor radar observations. J Atmos Sol Terr Phys 73:678-685

Guharay A, Batista PP, Clemesha BR, Sarkhel S (2013) On the variability of the terdiurnal tide over a Brazilian equatorial station using meteor radar observations. J Atmos Sol Terr Phys 104:87-95. https://doi.org/10.1016/j. jastp.2013.08.021

Guharay A, Batista PP, Clemesha BR (2015) On the variability of the diurnal tide and coupling with planetary waves in the MLT over Cachoeira Paulista (22.7º, 45W). J Atmos Sol Terr Phys 133:7-17. https://doi.org/10.1016/j. jastp.2015.07.016

Guharay A, Batista PP, Buriti RA, Schuch NJ (2017) Signature of the quasi27-day oscillation in the MLT and its relation with solar irradiance and 
convection. J Atmos Sol Terr Phys 161:1-7. https://doi.org/10.1016/j.jastp .2017 .06 .001

Hernandez G, Smith RW, Fraser GJ, Jones WL (1992) Large-scale waves in the upper mesosphere at Antarctic high latitudes. Geophys Res Lett 19:1347-1350

Hocking WK, Fuller B, Vandepeer B (2001) Real-time determination of meteorrelated parameters utilizing modern digital technology. J Atmos Sol Terr Phys 63:155-169

Jacobi C, Krug A, Merzlyakov E (2017) Radar observations of the quarterdiurnal tide at midlatitudes: seasonal and long-term variations. J Atmos Sol Terr Phys 163:70-77. https://doi.org/10.1016/j.jastp.2017.05.014

Kovalam S, Vincent RA (2003) Intradiurnal wind variations in the midlatitude and high-latitude mesosphere and lower thermosphere. J Geophys Res 108(D4):4135-4147. https://doi.org/10.1029/2002JD002500

Morton YT, Mathews JD, Zhou Q (1993) Further evidence for a 6-h tide above Arecibo. J Atmos Terr Phys 55(3):459-465. https://doi.org/10.1016/00219169(93)90081-9

Reddi CR, Rajeev K, Geetha R (1993) Tidal winds in the radio meteor region over Trivandrum $\left(8.5^{\circ} \mathrm{N}, 77^{\circ} \mathrm{E}\right)$. J Atmos Sol Terr Phys 55:1219-1231

Revah I (1969) Etude des vents de petite, échelle observes au moyen des trainees meteoriques. Ann Geophys 25(1):1-45

She CY, Chen S, Williams BP, Hu Z, Krueger DA, Hagan ME (2002) Tides in the mesopause region over Fort Collins, Colorado $\left(41^{\circ} \mathrm{N}, 105^{\circ} \mathrm{W}\right)$ based on lidar temperature observations covering full diurnal cycles. J Geophys Res 107(D18):4350-4361. https://doi.org/10.1029/2001JD001189
Sivjee GG, Walterscheid RL (1994) Six-hour zonally symmetric tidal oscillations of the winter mesopause over the South Pole Station. Planet Space Sci 42(6):447-453

Smith AK, Pancheva DV, Mitchell NJ (2004) Observations and modeling of the 6-hour tide in the upper mesosphere. J Geophys Res 109:D10105. https:// doi.org/10.1029/2003JD004421

Strobel DF (1978) Parameterization of the atmospheric heating rate from 15 to $120 \mathrm{~km}$ due to $\mathrm{O}_{2}$ and $\mathrm{O}_{3}$ absorption of solar radiation. J Geophys Res 83:6225-6230

Tong YU, Mathews JD, Ying W-P (1988) An upper E region quarterdiurnal tide at Arecibo? J Geophys Res 93:10047-10051

Walterscheid RL, Sivjee GG (1996) Very high frequency tides observed in the airglow over Eureka $\left(80^{\circ}\right)$. Geophys Res Lett 23:3651-3654. https://doi. org/10.1029/96GL03482

Walterscheid RL, Sivjee GG (2001) Zonally symmetric oscillations observed in the airglow from South Pole station. J Geophys Res 106(A):3645-3654. https://doi.org/10.1029/2000JA000128

Xu J, Smith AK, Jiang G, Yuan W, Gao H (2012) Features of the seasonal variation of the semidiurnal, terdiurnal and 6-h components of ozone heating evaluated from Aura/MLS observations. Ann Geophys 30:259-281. https ://doi.org/10.5194/angeo-30-259-2012

Xu J, Smith AK, Liu M, Liu X, Gao H, Jiang G, Yuan W (2014) Evidence for nonmigrating tides produced by the interaction between tides and stationary planetary waves in the stratosphere and lower mesosphere. J Geophys Res 119:471-489. https://doi.org/10.1002/2013JD020150

\section{Submit your manuscript to a SpringerOpen ${ }^{\circ}$ journal and benefit from:}

- Convenient online submission

- Rigorous peer review

- Open access: articles freely available online

- High visibility within the field

- Retaining the copyright to your article

Submit your next manuscript at $\boldsymbol{\nabla}$ springeropen.com 